\title{
Screening significantly hypermethylated genes in fetal tissues compared with maternal blood using a methylated-CpG island recovery assay-based microarray
}

\author{
Aihua Yin ${ }^{1,2+}$, Xiangzhong Zhang ${ }^{3 \dagger}$, Jing Wu', Li Du', Tianwen $\mathrm{He}^{1}$ and Xiaozhuang Zhang ${ }^{2^{*}}$
}

\begin{abstract}
Background: The noninvasive prenatal diagnosis procedures that are currently used to detect genetic diseases do not achieve desirable levels of sensitivity and specificity. Recently, fetal methylated DNA biomarkers in maternal peripheral blood have been explored for the noninvasive prenatal detection of genetic disorders. However, such efforts have covered only chromosomal aneuploidy, and fetal methylated DNA biomarkers in maternal whole blood for detecting single-gene diseases remain to be discovered.

Methods: To address this issue, we systematically screened significantly hypermethylated genes in fetal tissues and compared them with maternal peripheral blood potential in an attempt to detect fetal genes in maternal peripheral blood. First, the methylated-CpG island recovery assay combined with a CpG island array was performed for four fetus-toward placental tissues and the corresponding maternal peripheral bloods. Subsequently, direct bisulfite sequencing and combined bisulfite restriction analysis (COBRA) were carried out to validate the methylation status of the hypermethylated genes that were identified by the microarray analysis.

Results: Three hundred and ten significantly hypermethylated genes in the placental tissues were detected by microarray. From the top 15 hypermethylated genes detected by microarray, two were selected for sequencing validation in placental tissue and chorionic villus samples and four were selected for COBRA validation in four placental tissues, ten amniotic fluids and five chorionic villus samples. The six selected genes were confirmed to be hypermethylated in placental tissue and chorionic villus samples, but methylation of the genes could not be detected in the amniotic fluids.

Conclusions: Of the many hypermethylated genes and methylation sites that were found in the fetal tissues, some have great potential to be developed into molecular markers for noninvasive prenatal diagnosis of monogenic disorders. Further clinical studies are warranted to confirm these findings.
\end{abstract}

Keywords: $\mathrm{CpG}$ islands methylation, Methyl-CpG binding protein, Microarray, Combined bisulfite restriction analysis

\footnotetext{
*Correspondence: zhangxiaozhuang55@126.com

${ }^{\dagger}$ Equal contributors

${ }^{2}$ Maternal and Children Metabolic-Genetic Key Laboratory, Guangdong

Women and Children Hospital, Guangzhou, Guangdong 510010, China

Full list of author information is available at the end of the article
} 


\section{Background}

Definitive prenatal diagnosis of genetic diseases usually requires obtaining fetal genetic material by invasive procedures such as amniocentesis, chorionic villus sampling and cordocentesis. These invasive procedures put the fetus at a small but significant risk and, therefore, are carried out only when the risk of abnormal pregnancy, estimated by maternal age, ultrasonography and other noninvasive methods, outweighs the risk of miscarriage caused by such procedures [1]. Noninvasive procedures are also available for prenatal diagnosis. These procedures use maternal periphery blood samples and quantify maternal serum proteins that are surrogate markers of the underlying genetic abnormality. Such noninvasive diagnostic procedures do not achieve the desirable levels of sensitivity and specificity, and they are not definitive [2]. For these reasons, great efforts have been made in the last decade to develop fetal molecular biomarkers for noninvasive prenatal diagnosis.

The discovery of circulating fetal free DNA in the plasma of pregnant women opened up new doors for noninvasive prenatal diagnosis [3]. Early studies have mainly examined gender and polymorphic differences between the fetus and its mother. Fetal molecular biomarkers based on differences of this kind can be used only to detect paternally inherited disease [4,5]. In 2002, Poon et al.[6] first demonstrated that methylation differences between fetal DNA and maternal whole blood DNA could potentially be used as universally applicable fetal molecular markers for noninvasive prenatal diagnosis. Since then, a number of studies have focused on the identification of differential methylation patterns between the fetus and the maternal peripheral blood $[7,8]$. Recently, Papageorgiou et al. [9] used methylated DNA immunoprecipitation (MeDiP) coupled with highresolution tiling oligonucleotide array analysis to identify more than 2,000 differentially methylated regions (DMR) between female whole blood and placental DNA on chromosomes 13, 18, 21, X, and Y. In a subsequent study, they achieved the noninvasive prenatal detection of trisomy 21 by determining the fetal-specific DMRs present in the maternal peripheral blood of normal and trisomy 21 cases [10]. These studies were targeted towards the noninvasive prenatal detection of chromosomal aneuploidy and not towards single-gene genetic diseases.

In the present study, we systematically searched for potential methylation biomarkers for the noninvasive prenatal genetic detection of various inherited diseases, including single-gene genetic diseases and chromosomal aneuploidy. First, we used the methylated-CpG island recovery assay (MIRA) to capture methylated DNA. Then we performed a long oligonucleotide microarray analysis to characterize methylation patterns in the placenta at the first, second and third trimester of pregnancy. The microarray contained $60 \mathrm{k} 60$-mer probes that interrogate 4,162 genes distributed on the 23 pairs of chromosomes. The MIRA assay is based on the high affinity of the methyl-CpG-binding domain (MBD) protein which specifically recognizes methylated CpG dinucleotides [11-13]. Papageorgiou et al. [14-16] used 5-methylcytosinespecific antibodies to enrich methylated DNA; however, their method requires single-stranded DNA for recognition. Compared to this approach, the MIRA-based approach that we have proposed is more specific and more efficient in enriching methylated $\mathrm{CpG}$ islands on a genome-wide basis [12].

\section{Methods}

\section{Samples}

Seven pairs of samples of matched maternal peripheral blood and fetus-toward placental tissue were obtained from seven healthy pregnant women. Four of the pairs were randomly selected for microarray analysis and combined bisulfite restriction analysis (COBRA); the three other pairs were used to confirm the bisulfite sequencing. Maternal peripheral bloods were collected in the fasting state before delivery, and placental tissues were sampled within $30 \mathrm{~min}$ of delivery. Five chorionic villus and ten amniotic fluid samples were collected in first-trimester and second-trimester pregnancies respectively, to validate the methylation status of the hypermethylated genes identified using the microarray. Before the samples were used in this study, the following diseases were excluded using the retrospective clinical criteria: pre-eclampsia, gestational diabetes, intrauterine growth restriction, preterm delivery and spontaneous abortion after detection of a fetal structural or chromosomal abnormality. All samples were snap-frozen in liquid nitrogen within $6 \mathrm{hrs}$ of collection and stored at $-80^{\circ} \mathrm{C}$ until the DNA was isolated. The experiments were approved by the Ethics Committee at the Guangdong Women and Children Hospital. Informed written consent was obtained from all participants.

\section{MIRA microarray analysis of DNA methylation}

The MIRA-based microarray analysis was performed as described previously [17] with minor modifications. Briefly, DNA was first separated from four pairs of matched fresh-frozen maternal peripheral blood and placental tissue samples using the standard phenol/chloroform technique. Then $2 \mu \mathrm{g}$ of the genomic DNA samples were sheared into 200-1000 bp fragments by Mse I (5'TTAA) and purified to remove any fragments smaller than 100 bp using a MicroDNA Purification Kit (CoWin Biotech Company, Beijing, China) following the manufacturer's instruction. Afterwards, the purified DNA fragments were used to enrich methylated DNA using a 
MBD kit (BioChain, Hayward, CA, USA) according to the manufacturer's protocol. The MIRA-captured DNA segments were purified and amplified using GenomePlex Whole Genome Amplification Kit (Sigma) as per the supplier's instruction. The products of whole genome amplification from the total input DNA without MBD enrichment and methylation-enriched DNA from each of the samples were labeled with cy3-dCTP and cy5dCTP respectively, using Klenow enzyme (Takara, Dalian, China). The fluorescent dye labeled DNA was mixed and hybridized to Agilent human CpG island microarrays that were designed to interrogate 61,982 CpG dinucleotides covering 4,162 genes. After hybridization, the slides were washed and scanned on the Agilent microarray platform according to Agilent's standard protocol. The data were extracted using Agilent Feature Extraction software. Following global mean normalization, faint probes with intensity $<400$ were discarded and excluded from the analysis. Unsupervised clustering analysis was performed using the Cluster software. Probes were considered positive for differential methylation between maternal blood and placental tissue if the fold changes in their MIRA/Input signaling ratios between the placental tissue and the maternal blood were $>1.2$ or $<0.83$ (q <0.05) using SAM (significance analysis of microarrays) [18]. The significant enrichment of the Gene Ontology (GO) terms associated with the hypermethylated genes was analyzed using the hypergeometric distribution in the $\mathrm{R}$ language software package. All microarray data have been submitted to the Gene Expression Omnibus [GEO: GSE35997].

\section{Validation of hypermethylated genes using direct bisulfite sequencing}

Of the top 15 hypermethylated genes identified by the methylation microarray analysis, two significantly hypermethylated genes (NR2F2 and TFAP2C) were selected for further validation in independent samples using direct bisulfite sequencing. Briefly, genomic DNA was bisulfite converted using the DNA methylation detection kit (BioChain, Hayward, CA, USA) as per manufacturer's protocol. Then, $125 \mathrm{ng}$ of bisulfite converted DNA was PCR amplified in $50 \mu \mathrm{L}$ reaction mixture containing $1 \times$ PCR Buffer (Mg2+ Plus), $200 \mu \mathrm{M}$ of each dNTP, $0.5 \mu \mathrm{M}$ of forward and reverse primers (primer sequences are provided in Table 1) and 1.25 units of TaKaRa Taq HS. The PCR cycling conditions were: $94^{\circ} \mathrm{C}$ for $5 \mathrm{~min} ; 45 \times\left(94^{\circ} \mathrm{C}\right.$ for $30 \mathrm{~s}, 55^{\circ} \mathrm{C}$ for $30 \mathrm{~s}, 72^{\circ} \mathrm{C}$ for $30 \mathrm{~s}) ; 72^{\circ} \mathrm{C}$ for $7 \mathrm{~min}$, and $4^{\circ} \mathrm{C}$ hold. The PCR products were cleaned using a MicroDNA Purification Kit. The purified PCR products were then subjected to direct sequencing in an ABI 3500xL Genetic Analyzer using the same forward primers that were used for the PCR amplification (Table 1).
Table 1 Primer pairs used for direct bisulfite sequencing and combined bisulfite restriction analysis of hypermethylated genes

\begin{tabular}{|c|c|c|c|}
\hline Gene & $\begin{array}{l}\text { GenBank } \\
\text { Accession No. }\end{array}$ & & Primer $\left(5^{\prime} \rightarrow 3^{\prime}\right)$ \\
\hline \multirow[t]{2}{*}{ PITX2 } & NM_000325.5 & $\mathrm{F}$ & TAGTGATAGGCGTTTCGGGTT \\
\hline & & $\mathrm{R}$ & CCACTACATACTAACAAACACTCAAAT \\
\hline \multirow[t]{2}{*}{$T L X 3$} & NM_021025 & $\mathrm{F}$ & TCGGTTGAGGATTAGAGGGATT \\
\hline & & $\mathrm{R}$ & AACGCCACCTAACCATCTATTC \\
\hline \multirow[t]{2}{*}{ OTX2 } & NM_172337.1 & $\mathrm{F}$ & AGTTGTGTTAGGTTGAGGGAG \\
\hline & & $\mathrm{R}$ & AATCCCAAAAACCTITITAAA \\
\hline \multirow[t]{2}{*}{ MNX1 } & NM_001165255 & $\mathrm{F}$ & TTAAGAAATAGCGAGAGGGAG \\
\hline & & $\mathrm{R}$ & AAACGCTCGTAACATAATCCC \\
\hline \multirow[t]{2}{*}{$N R 2 F 2$} & NM_001145155 & $\mathrm{F}$ & CGTATCGTGGATTTGGAGTAGGGTATT \\
\hline & & $\mathrm{R}$ & AACAAACTCGCTAACAAATAAACRACATT \\
\hline \multirow[t]{2}{*}{ TFAP2C } & NM_003222 & $\mathrm{F}$ & CGAAGTGTTAGGGTTTTGTGTGT \\
\hline & & $\mathrm{R}$ & CGACCTTAAACAACAACCAAATCC \\
\hline
\end{tabular}

\section{Validation of hypermethylated genes using COBRA}

COBRA was used to validate the methylation status of four of the genes (PITX2, TLX3, OTX2 and MNX1) from among the top 15 hypermethylated genes [19]. The principle of the COBRA method is that the cytosine in DNA is converted to uracil by bisulfite treatment while methylated cytosine is retained as cytosine. Thus, methylated and unmethylated cytosines can be distinguished by digesting the DNA with a restriction enzyme that recognizes sequences containing CPG. For the COBRA assays, the bisulfite conversion, PCR amplification and purification were carried out as described above. The primer sequences used for the COBRA validation are listed in Table 1. The purified PCR products were digested with the BstU I (CG $\downarrow C G)$ restriction enzyme (New England Biolabs, Ipswich, MA, US) and then electrophoresed on $2 \%$ agarose gels supplemented with ethidium bromide for visualization under a UV light.

\section{Results}

\section{MIRA microarray analysis of DNA methylation}

To screen hypermethylated genes in fetal tissue relative to those in maternal circulation, we used an MIRA approach to identify significantly hypermethylated genes in four placental tissue samples and the four corresponding maternal peripheral blood samples. First, we performed an unsupervised clustering analysis on 9382 probes with intensities that were greater than 400 in at least one of the samples. This analysis showed that there was distinct clustering of the maternal peripheral blood and placental tissue samples (Figure 1), suggesting that there were obvious differences of methylation between the maternal peripheral blood and the placental tissue. 


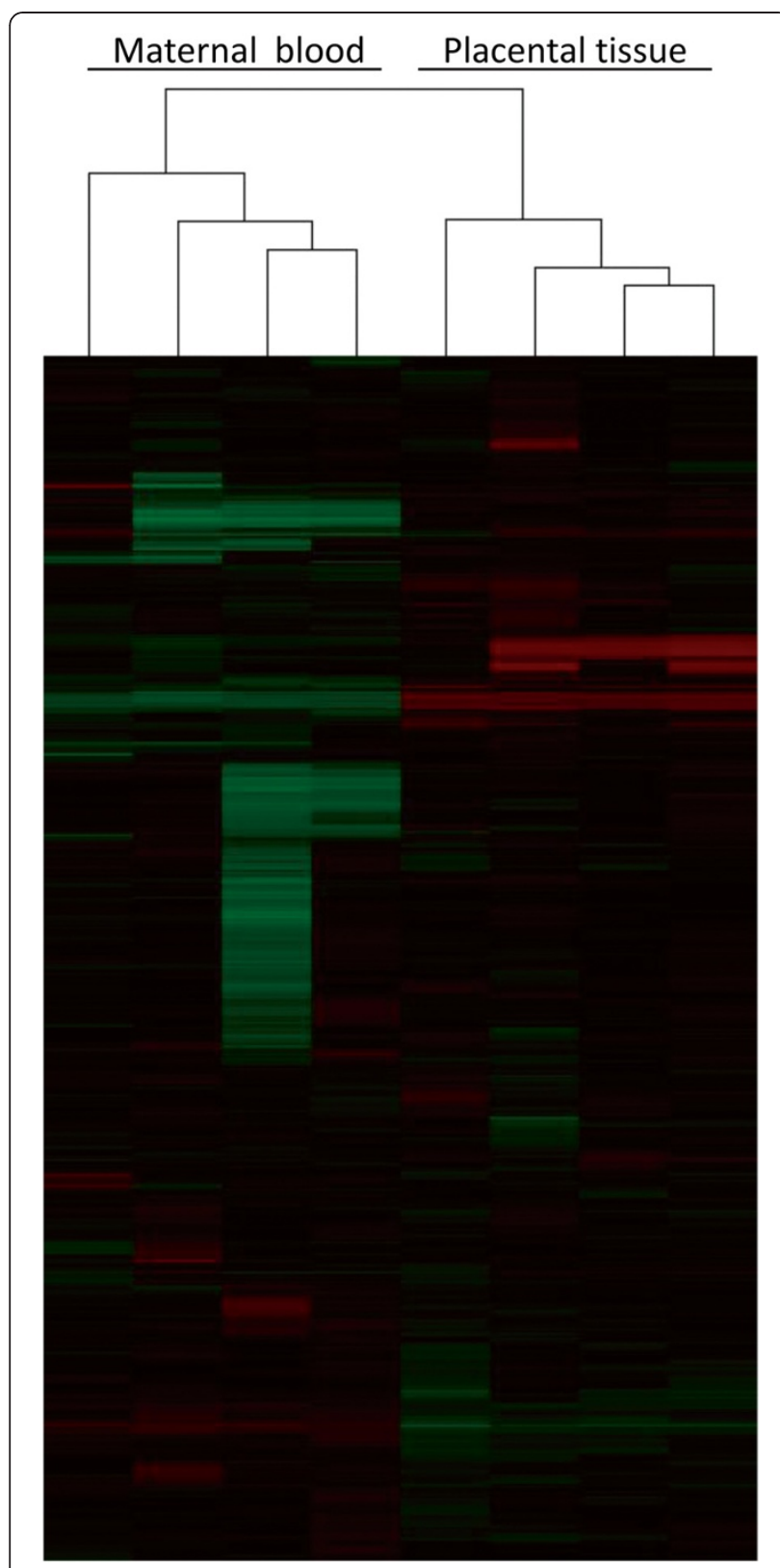

Figure 1 Unsupervised clustering in four pairs of matched placental tissue and maternal peripheral blood samples.

The methylation difference, represented by copy number difference of MBD protein enriched DNA in MIRA approach, is similar to the DNA copy number difference in array-based comparative genomic hybridization $(\mathrm{aCGH})$ and is quite different from the gene expression for one copy of DNA expresses various copies of mRNA. In the well-established aCGH method, the cutoff for detecting DNA copy differences is usually set to be $>1.25$ of probe ratio value [20,21]. This cutoff is lower than the one used in mRNA expression profiling analysis where the alteration ratio is usually set to be $>2.0$. In the present study, SAM analysis was performed based on the cutoff criteria that fold changes in MIRA/Input signaling ratios between placental tissues versus maternal bloods were $>1.2$ or $<0.83$ ( $q<0.05$ ). We detected 3,774 positive probes corresponding to 783 differentially methylated genes; of these, 310 genes had at least two positive probes with fold changes in the MIRA/Input signaling ratios between placental tissues and maternal bloods that were above 1.2 ( $\mathrm{q}<0.05)$. The 310 genes were selected as hypermethylated genes (Additional file 1: Table S1). The top 15 hypermethylated genes had more than ten positive probes and are listed in Table 2.

The significant enrichment analysis of the GO terms for the differentially methylated genes demonstrated that the 783 differentially methylated genes were involved in many important biological processes such as regulation of transcription and organismal development (Figure 2).

\section{Validation of hypermethylated genes using direct bisulfite sequencing}

Bisulfite sequencing allows the methylation analysis of the cytosine residues in a given sequence. Two protocols have been employed for bisulfite sequencing: cloningbased sequencing and direct PCR sequencing. Cloningbased sequencing is very useful in determining the pattern of mosaic methylation of individual molecules. However, it is labor-intensive and time-consuming because it requires the cloning of the PCR product before sequencing and usually the sequences of at least ten individual clones are required to provide an accurate estimate of methylation in the population of molecules. Direct PCR sequencing only provides the averaged methylation status in a population of molecules but this method is convenient for the rapid assessment of global methylation levels in a population of molecules. In this study, direct bisulfite sequencing was performed to validate the reliability of the methylation microarray analysis. Two genes, TFAP $2 C$ and NR2F2, from the top 15 hypermethylated genes identified by MIRA analysis were selected for methylation validation in maternal peripheral blood, placental tissue and chorionic villus samples. The sequencing results indicated that TFAP2C and $N R 2 F 2$ were hypomethylated at multiple CpGs sites in maternal peripheral blood samples and hypermethylated at multiple CpGs sites in the placental tissue and chorionic villus samples (Figure 3 ) of fetal origin.

\section{Validation of hypermethylated genes using COBRA}

COBRA is a sensitive and convenient assay to measure DNA methylation status at specific gene loci in small amounts of genomic DNA [22,23]. COBRA has been widely used for confirming methylation results obtained by microarray analysis $[12,24]$. Here the COBRA assay was used to validate the reliability of the methylation microarray analysis and to screen for fetal methylation 
Table 2 Top 15 hypermethylated genes identified using the MIRA-based microarray

\begin{tabular}{|c|c|c|c|c|c|}
\hline Gene & $\begin{array}{l}\text { Changed } \\
\text { probes }\end{array}$ & $\begin{array}{l}\text { Average } \\
\text { ratio }^{\mathrm{a}}\end{array}$ & Position $^{\text {b }}$ & Gene description & Phenotype MIM Accession No. ${ }^{c}$ \\
\hline PITX2 & 27 & 3.19 & I and D & Paired-like homeodomain 2 & $180500,137600,604229,180550$ \\
\hline PAX6 & 20 & 2.34 & $P$ and $I$ & Paired box 6 & $\begin{array}{l}\text { 106210, 604219, 120430, 120200, } \\
136520,206700,148190,165550,604229\end{array}$ \\
\hline NR2F2 & 17 & 3.22 & $P, I$ and $D$ & Nuclear receptor subfamily 2 , group F, member 2 & \\
\hline MNX1 & 15 & 2.50 & $P, I$ and $D$ & Motor neuron and pancreas homeobox 1 & 176450 \\
\hline TLX3 & 15 & 3.69 & $P$ and $D$ & T-cell leukemia homeobox 3 & \\
\hline PAX9 & 15 & 2.33 & $P$ and $I$ & Paired box 9 & 604625 \\
\hline SALL1 & 15 & 2.27 & $P, I$ and $D$ & Sal-like 1 (Drosophila) & 107480 \\
\hline MADIL1 & 14 & 3.18 & 1 & MAD1 mitotic arrest deficient-like 1 (yeast) & 176807 \\
\hline TBX3 & 14 & 4.50 & $P, I$ and $D$ & T-box 3 & 181450 \\
\hline$H L X$ & 14 & 2.01 & $P, I$ and $D$ & H2.0-like homeobox & \\
\hline PDX1 & 13 & 2.88 & $P, I$ and $D$ & Pancreatic and duodenal homeobox 1 & $606392,260370,125853$ \\
\hline TFAP2C & 13 & 4.78 & P & Transcription factor AP-2 gamma & \\
\hline$S I X 1$ & 12 & 3.13 & $P, I$ and $D$ & SIX homeobox 1 & 608389,605192 \\
\hline SIM1 & 12 & 2.98 & $P$ and $I$ & Single-minded homolog 1 (Drosophila) & 601665 \\
\hline OTX2 & 12 & 3.39 & $P$ and $D$ & Orthodenticle homeobox 2 & 610125,613986 \\
\hline
\end{tabular}

Several probes for each gene are present on the microarray. ${ }^{\mathrm{a}}$ The average ratio of the probe density of the positive probe in placental tissue to that in the maternal peripheral blood calculated using the SAM software. ${ }^{b}$ The letters in this column refer to different regions of the gene: $\mathrm{P}$, promoter; I, inside; $\mathrm{D}$, downstream. 'The phenotype MIM Accession Number is from the OMIM database (www.ncbi.nlm.nih.gov/omim).

biomarkers. Four genes from the top 15 hypermethylated genes were selected for validation in four pairs of matched placental tissue and maternal peripheral blood samples. The results in Figure 3 show that PITX2, TLX3, OTX2 and MNX1 were all methylated in placental tissues but not in maternal peripheral bloods. Because the placental tissues are at a late stage of fetus development, we also measured the methylation status of these four genes in ten amniotic fluid and five chorionic villus samples using a COBRA assay to assess the methylation status at the early and middle stages of fetus development. The results showed that PITX2, TLX3, OTX2 and MNX1 were also methylated in all the chorionic villus samples tested (Figure 4), but were not methylated in the majority of the tested amniotic fluid samples.

\section{Discussion}

The MIRA microarray does not require restriction endonuclease, antibody or bisulfite treatment of the genomic DNA and, therefore, offers many advantages over existing methods for the genome-wide screening of DNA methylation. MIRA microarrays have been used to identify candidate methylation biomarker for cancer diagnosis $[12,25]$. In this study, we applied this approach to seek candidate biomarkers for noninvasive prenatal diagnosis. Currently, noninvasive prenatal screening typically involves a combination of ultrasound tests and the measurement of non-specific maternal serum markers. These screening tests are limited to trisomies of chromosomes 21 and 18 and do not reliably diagnose or exclude these types of abnormalities. The discovery of fetal DNA in maternal plasma opened new doors for non-invasive prenatal diagnosis. However, the presence of background maternal DNA interferes with the analysis of fetal DNA which usually constitutes less than $10 \%$ of the total circulating free DNA in early pregnancy [26]. This has posed significant technical hurdles for the detection of fetal genetic loci that are not completely absent from the maternal genome using current PCRbased approaches [27]. To overcome this problem, the differential methylation between placentally and maternally derived cell-free DNA sequences has been investigated [28]. Many studies have shown that these epigenetic differences may serve as potential fetal molecular markers for noninvasive prenatal diagnosis $[7,8]$. However, only a limited number of genomic regions have been identified or tested so far and the majority of studies have focused only on fetal chromosomal aneuploidy detection, for example, of chromosomes 21 and 18. Here, we aimed to identify methylation biomarkers for the prenatal diagnosis of not only fetal chromosomal aneuploidies but also of monogenic diseases at a genome-wide level.

Promoter methylation plays important roles in regulating gene expression both in development and in human disease and, so far, DNA methylation studies have mainly been focused on the promoter regions of genes. Recently, methylation of the gene body (sometimes 


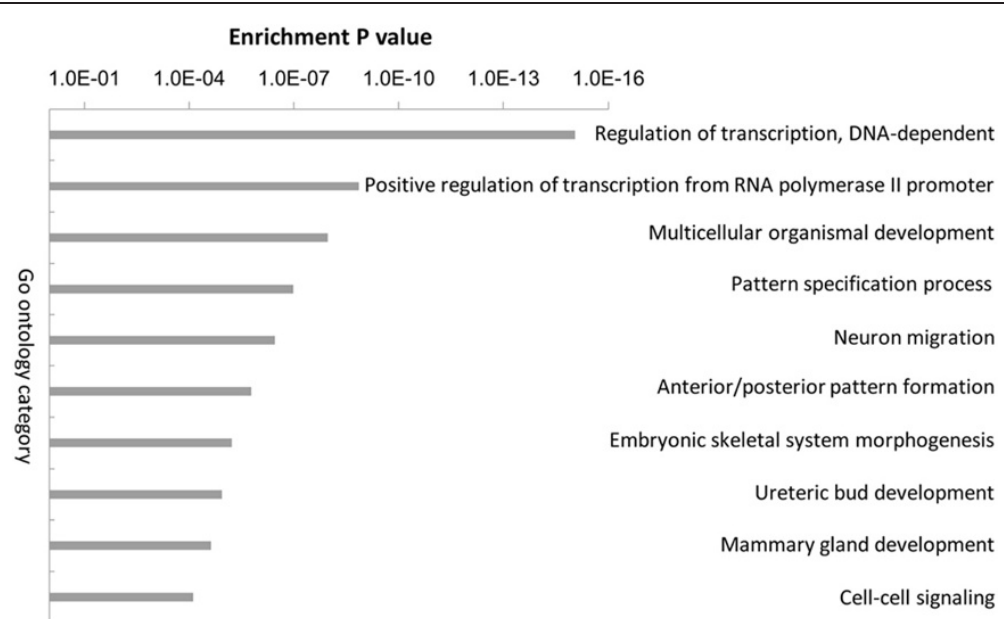

Figure 2 Gene ontology categories enriched in differentially methylated genes between placental tissues and maternal peripheral blood.

called intragenic methylation) has been reported to play a role in transcriptional regulation and efficiency [29] and intragenic methylation is attracting increasing attention. Therefore, in this study, we investigated the hypermethylation of genes based on the methylation status of both the promoter and the gene body.

Large differences were observed in methylation patterns between maternal peripheral blood and placental tissue. Further analysis based on GO terms revealed that many of the differentially methylated genes were involved in regulation of transcription and multicellular organismal. This result might suggest that the differentially methylated genes contribute to the control of gene expression during embryonic development. It is well known that DNA methylation changes during embryonic development are frequent events that play major roles in regulating gene expression and other developmental processes. It is worth noting that differentially methylated genes were involved in mammary gland development (Figure 2). This finding suggested that methylation may play major roles in regulating lactation.

The bisulfite sequencing and COBRA assays both confirmed that the observed genes were hypermethylated in placental tissue and chorionic villus; however, the DNA methylation was unobvious in the amniotic fluid samples. The placental tissue samples, obtained immediately after delivery, are from a late-stage placenta and the chorionic villus tissue samples are from an early-stage placenta, the amniotic fluid is not a placental tissue. The cells in amniotic fluid are an admixture of various cells from various fetal tissues, mainly fibroblasts, epithelial cells and amniocytes that are shed from the fetus

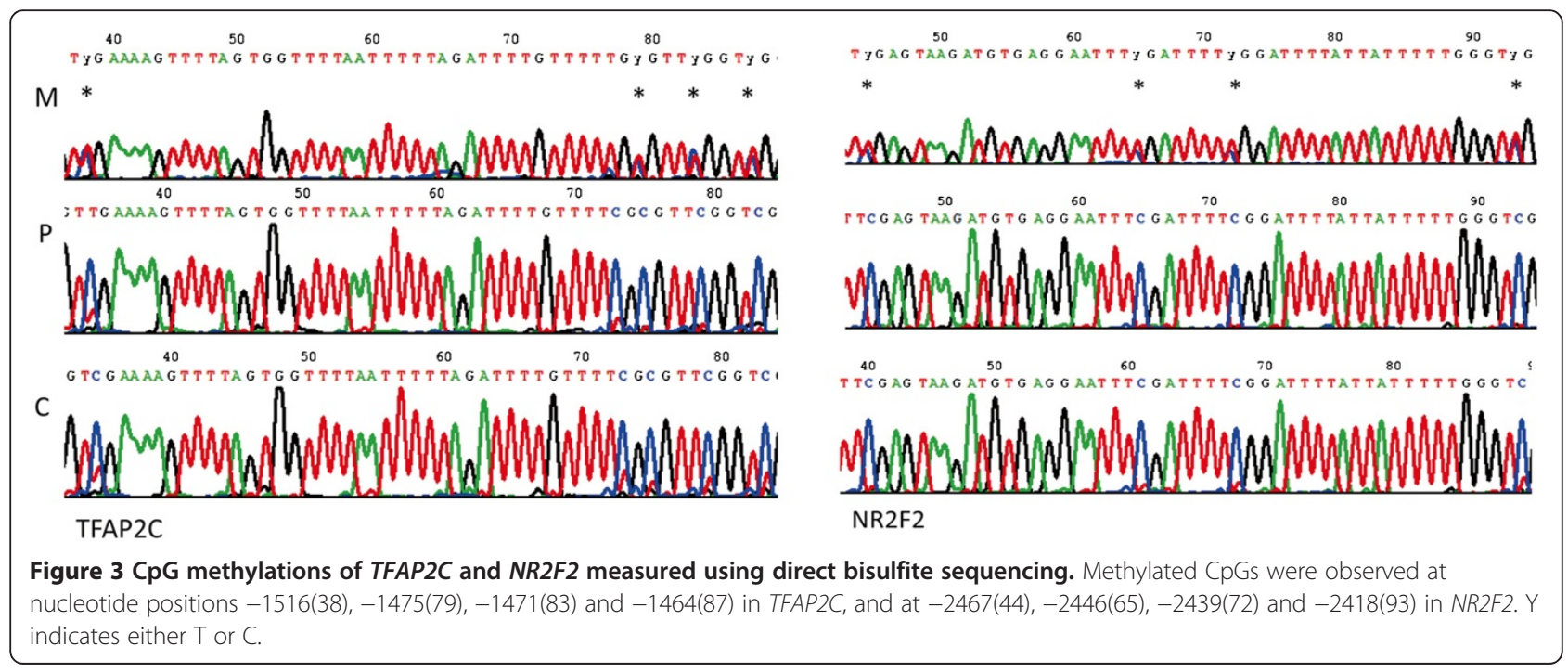




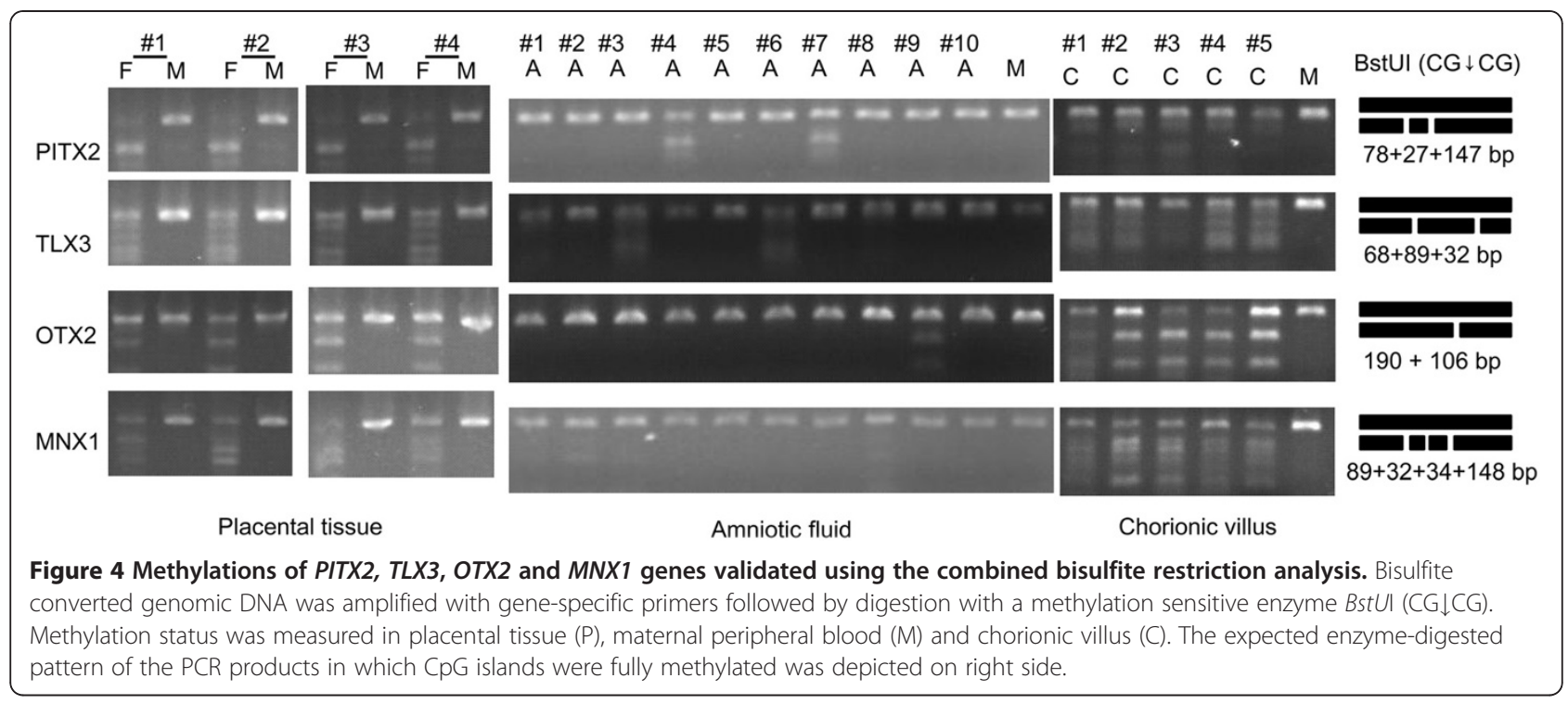

surface. Therefore, we concluded that the observed methylation differences in these samples may reflect tissue specificity rather than developmental specificity.

Previous studies have shown that the circulating fetal DNA in maternal peripheral blood are mainly from the placenta [30] because the placenta is the only channel for nutrient transport between mother and fetus. The DNA in different tissues carries the same sequence information, no matter whether the sequences are methylated or not. Therefore, the detection of fetal methylated DNAs in maternal peripheral blood will yield fetal information about genetic variations that may be useful for the diagnosis of fetal genetic diseases. Furthermore, it is convenient and feasible to discriminate between fetal methylated DNA and maternal nonmethylated DNA in maternal peripheral blood based on differences in their methylation patterns. Thus, the observed methylation differences of disease-associated genes between placental tissue and maternal peripheral blood provide a foundation for developing novel methods for the detection of fetal genes in maternal peripheral blood.

We identified a large number of hypermethylated genes in fetal tissues; most of these genes have been recorded in the Online Mendelian Inheritance in Man (OMIM) database (www.ncbi.nlm.nih.gov/omim) where the relationship between abnormalities in these genes and diseases has been defined. For example, mutations in PITX2, a homeobox gene, are known to contribute to Axenfeld-Rieger syndrome (ARS), an autosomaldominant developmental disorder [31,32]. The hypermethylated genes have great potential to be developed into molecular markers for noninvasive prenatal diagnosis of monogenic disorders. In a future study, we will use the MBD protein to enrich fetal hypermethylated DNA fragments in maternal peripheral blood and further explore the feasibility of using these hypermethylated genes as biomarkers for noninvasive prenatal diagnosis in large samples.

\section{Conclusions}

In this study we identified a lot of hypermethylated genes and methylation sites in fetal tissues. Some of the hypermethylated genes have great potential to be developed into molecular markers for noninvasive prenatal diagnosis of monogenic disorders. Further clinical studies are warranted to confirm these findings.

\section{Additional file}

Additional file 1: Table S1. List of the hypermethylated genes in placental tissue identified by MIRA based microarray.

\section{Abbreviations}

COBRA: Combined bisulfite restriction analysis; MIRA: Methylated-CpG island recovery assay.

\section{Competing interest}

The authors declare that they have no competing interests.

\section{Authors' contributions}

$X Z$ Zhang, AH Yin and XZ Zhang defined the research theme. AH Yin, XZ Zhang, J Wu, L Du and TW He performed the experimental work and organized the data. AH Yin and XZ Zhang designed experiments, interpreted data and drafted the manuscript. XZ Zhang critically reviewed the manuscript and provided concepts. All authors read and approved the final manuscript.

\section{Acknowledgements}

This project was supported by the National Science Foundation for Young Scholars of China (Grant No. 81000255). We thank Dr. Liang Zhang and BioChain (Beijing) Science \& Technology Inc. for technical assistance.

\section{Author details}

${ }^{1}$ Prenatal Diagnosis Centre, Guangdong Women and Children Hospital, Guangzhou, Guangdong 510010, China. 'Maternal and Children MetabolicGenetic Key Laboratory, Guangdong Women and Children Hospital, 
Guangzhou, Guangdong 510010, China. ${ }^{3}$ Department of Hematology, The Third Affiliated Hospital of Sun Yat-sen University, Guangzhou, Guangdong 510630, China.

Received: 8 March 2012 Accepted: 8 June 2012

Published: 18 June 2012

\section{References}

1. Lo YM: Noninvasive prenatal detection of fetal chromosomal aneuploidies by maternal plasma nucleic acid analysis: a review of the current state of the art. BJOG 2009, 116(2):152-157.

2. Malone FD, Canick JA, Ball RH, Nyberg DA, Comstock CH, Bukowski R, Berkowitz RL, Gross SJ, Dugoff L, Craigo SD, et al: First-trimester or secondtrimester screening, or both, for Down's syndrome. N Engl J Med 2005, 353(19):2001-2011.

3. Lo YM, Corbetta N, Chamberlain PF, Rai V, Sargent IL, Redman CW, Wainscoat JS: Presence of fetal DNA in maternal plasma and serum. Lancet 1997, 350(9076):485-487.

4. Ng EK, Tsui NB, Lau TK, Leung TN, Chiu RW, Panesar NS, Lit LC, Chan KW, Lo YM: mRNA of placental origin is readily detectable in maternal plasma. Proc Natl Acad Sci U S A 2003, 100(8):4748-4753.

5. Tsui NB, Chim SS, Chiu RW, Lau TK, Ng EK, Leung TN, Tong YK, Chan KC, Lo YM: Systematic micro-array based identification of placental mRNA in maternal plasma: towards non-invasive prenatal gene expression profiling. J Med Genet 2004, 41(6):461-467.

6. Poon LL, Leung TN, Lau TK, Chow KC, Lo YM: Differential DNA methylation between fetus and mother as a strategy for detecting fetal DNA in maternal plasma. Clin Chem 2002, 48(1):35-41.

7. Tsui DW, Chan KC, Chim SS, Chan LW, Leung TY, Lau TK, Lo YM, Chiu RW: Quantitative aberrations of hypermethylated RASSF1A gene sequences in maternal plasma in pre-eclampsia. Prenat Diagn 2007, 27(13):12121218.

8. Tong YK, Chiu RW, Leung TY, Ding C, Lau TK, Leung TN, Lo YM: Detection of restriction enzyme-digested target DNA by PCR amplification using a stem-loop primer: application to the detection of hypomethylated fetal DNA in maternal plasma. Clin Chem 2007, 53(11):1906-1914.

9. Papageorgiou EA, Fiegler H, Rakyan V, Beck S, Hulten M, Lamnissou K, Carter NP, Patsalis PC: Sites of differential DNA methylation between placenta and peripheral blood: molecular markers for noninvasive prenatal diagnosis of aneuploidies. Am J Pathol 2009, 174(5):1609-1618.

10. Papageorgiou EA, Karagrigoriou A, Tsaliki E, Velissariou V, Carter NP, Patsalis PC: Fetal-specific DNA methylation ratio permits noninvasive prenatal diagnosis of trisomy 21. Nat Med 2011, 17(4):510-513.

11. Gebhard C, Schwarzfischer L, Pham TH, Schilling E, Klug M, Andreesen R, Rehli M: Genome-wide profiling of CpG methylation identifies novel targets of aberrant hypermethylation in myeloid leukemia. Cancer Res 2006, 66(12):6118-6128.

12. Rauch $T$, Li H, Wu X, Pfeifer GP: MIRA-assisted microarray analysis, a new technology for the determination of DNA methylation patterns, identifies frequent methylation of homeodomain-containing genes in lung cancer cells. Cancer Res 2006, 66(16):7939-7947.

13. Rauch T, Wang Z, Zhang X, Zhong X, Wu X, Lau SK, Kernstine KH, Riggs AD, Pfeifer GP: Homeobox gene methylation in lung cancer studied by genome-wide analysis with a microarray-based methylated $\mathrm{CpG}$ island recovery assay. Proc Natl Acad Sci U S A 2007, 104(13):5527-5532.

14. Ching TT, Maunakea AK, Jun P, Hong C, Zardo G, Pinkel D, Albertson DG, Fridlyand J, Mao JH, Shchors K, et al: Epigenome analyses using BAC microarrays identify evolutionary conservation of tissue-specific methylation of SHANK3. Nat Genet 2005, 37(6):645-651.

15. Jacinto FV, Ballestar E, Ropero S, Esteller M: Discovery of epigenetically silenced genes by methylated DNA immunoprecipitation in colon cancer cells. Cancer Res 2007, 67(24):11481-11486.

16. Weber M, Davies JJ, Wittig D, Oakeley EJ, Haase M, Lam WL, Schubeler D: Chromosome-wide and promoter-specific analyses identify sites of differential DNA methylation in normal and transformed human cells. Nat Genet 2005, 37(8):853-862.

17. Rauch TA, Pfeifer GP: The MIRA method for DNA methylation analysis. Methods Mol Biol 2009, 507:65-75.

18. Tusher VG, Tibshirani R, Chu G: Significance analysis of microarrays applied to the ionizing radiation response. Proc Natl Acad Sci U S A 2001, 98(9):5116-5121.
19. Xiong Z, Laird PW: COBRA: a sensitive and quantitative DNA methylation assay. Nucleic Acids Res 1997, 25(12):2532-2534.

20. Richards AA, Santos LI, Nichols HA, Crider BP, Elder FF, Hauser NS, Zinn AR, Garg V: Cryptic chromosomal abnormalities identified in children with congenital heart disease. Pediatr Res 2008, 64(4):358-363.

21. Leung TY, Vogel I, Lau TK, Chong W, Hyett JA, Petersen OB, Choy KW: Identification of submicroscopic chromosomal aberrations in fetuses with increased nuchal translucency and apparently normal karyotype. Ultrasound Obstet Gynecol 2011, 38(3):314-319.

22. Cai HH, Sun YM, Miao Y, Gao WT, Peng Q, Yao J, Zhao HL: Aberrant methylation frequency of TNFRSF10C promoter in pancreatic cancer cell lines. Hepatobiliary Pancreat Dis Int 2011, 10(1):95-100.

23. Hassel JC, Sucker A, Edler L, Kurzen H, Moll I, Stresemann C, Spieth K, Mauch C, Rass K, Dummer R, et al: MGMT gene promoter methylation correlates with tolerance of temozolomide treatment in melanoma but not with clinical outcome. Br J Cancer 2010, 103(6):820-826.

24. Chen T, Williams TD, Mally A, Hamberger C, Mirbahai L, Hickling K, Chipman $\mathrm{JK}:$ Gene expression and epigenetic changes by furan in rat liver. Toxicology 2012, 292(2-3):63-70.

25. Wu X, Rauch TA, Zhong X, Bennett WP, Latif F, Krex D, Pfeifer GP: CpG island hypermethylation in human astrocytomas. Cancer Res 2010, 70 (7):2718-2727.

26. Lo YM, Tein MS, Lau TK, Haines CJ, Leung TN, Poon PM, Wainscoat JS, Johnson PJ, Chang AM, Hjelm NM: Quantitative analysis of fetal DNA in maternal plasma and serum: implications for noninvasive prenatal diagnosis. Am J Hum Genet 1998, 62(4):768-775.

27. Hahn S, Holzgreve W: Prenatal diagnosis using fetal cells and cell-free fetal DNA in maternal blood: what is currently feasible? Clin Obstet Gynecol 2002, 45(3):649-656. discussion 730-642.

28. Chim SS, Jin S, Lee TY, Lun FM, Lee WS, Chan LY, Jin Y, Yang N, Tong YK, Leung TY, et al: Systematic search for placental DNA-methylation markers on chromosome 21: toward a maternal plasma-based epigenetic test for fetal trisomy 21. Clin Chem 2008, 54(3):500-511.

29. Shenker N, Flanagan JM: Intragenic DNA methylation: implications of this epigenetic mechanism for cancer research. Br J Cancer 2012, 106(2):248-253.

30. Wataganara T, Bianchi DW: Fetal cell-free nucleic acids in the maternal circulation: new clinical applications. Ann N Y Acad Sci 2004, 1022:90-99.

31. Saadi I, Toro R, Kuburas A, Semina E, Murray JC, Russo AF: An unusual class of PITX2 mutations in Axenfeld-Rieger syndrome. Birth Defects Res A Clin Mol Teratol 2006, 76(3):175-181.

32. Vieira V, David G, Roche $\mathrm{O}$, de la Houssaye $G$, Boutboul $S$, Arbogast $L$, Kobetz A, Orssaud C, Camand O, Schorderet DF, et al: Identification of four new PITX2 gene mutations in patients with Axenfeld-Rieger syndrome. Mol Vis 2006, 12:1448-1460.

doi:10.1186/1755-8794-5-26

Cite this article as: Yin et al:: Screening significantly hypermethylated genes in fetal tissues compared with maternal blood using a methylated-CpG island recovery assay-based microarray. BMC Medical Genomics 2012 5:26.

\section{Submit your next manuscript to BioMed Central and take full advantage of:}

- Convenient online submission

- Thorough peer review

- No space constraints or color figure charges

- Immediate publication on acceptance

- Inclusion in PubMed, CAS, Scopus and Google Scholar

- Research which is freely available for redistribution 